\title{
Modelling and Simulation of the Coalescence of Two Different Polymer Grains
}

\author{
Sara Aid ${ }^{1}$, Anissa Eddhahak ${ }^{1}$, Zaida Ortega ${ }^{2}$, Daniel Froelich ${ }^{3}$, Abbas Tcharkhtchi ${ }^{1}$ \\ ${ }^{1}$ PIMM Laboratory, CNRS UMR 8006, Arts et Métiers ParisTech \\ 151 bd de l'Hôpital, 75013 Paris, France. \\ sara.aid@ensam.eu; anissa.eddhahak@ensam.eu; abbas.tcharkhtchi@ensam.eu \\ ${ }^{2}$ Calle Juan de Quesada, 35001 Las Palmas de Gran Canaria, Las Palmas, Spain \\ zaida.ortega@ulpgc.es \\ ${ }^{3}$ Institut de Chambéry, Arts et Métiers ParisTech \\ Savoie Technolac, rue du Lac Majeur F-73375 LE BOURGET DU LAC Cedex-Chambéry, France \\ daniel.froelich@ensam.eu
}

\section{Extended Abstract}

The present work focuses on the study of coalescence phenomenon of two different polymers the PolyVinyliDene Fluoride (PVDF), and Poly (methyl methacrylate) PMMA.

Different blends of PVDF/PMMA polymers (0\%, 10\%, 30\%, 70\%, 90\% and 100\%) have been compounded using single-screw extrusion process. Then the blends have been characterized by physico-chemical, thermal and thermomechanical methods; their rheological characteristics have been studied at molten state. These tests showed clearly the miscibility of PMMA and PVDF [1].

The coalescence tests have been performed on the grains of the initial polymers using a polarized light optical microscope combined by a hot stage, video camera and video capture software. The curves of coalescence were plotted using an image software analyzer. Different tests were carried out on different pairs of PVDF/PVDF, PMMA/PMMA and PVDF/PMMA. The effect of different parameters like temperature, particle size on the rate of coalescence was investigated. In order to follow the effect of the neighboring grains on the kinetic of coalescence of two grains a third grain has been put in contact with these two grains in different positions. The results show that the coalescence phenomenon is very sensitive to the temperature and depends mostly on it.

The second part of this study concerns the modeling of coalescence of the grains of different polymers. In previous works, our researcher group used the Bellehumeur's model [2] for modelling the coalescence rate of two particles of the same polymer (PP, PVDF and PMMA) [3]. They studied the effect of viscosity, surface tension and relaxation time of the polymer on coalescence phenomenon.

The novelty studied in this work is the modeling of the coalescence of two different polymers which exhibit different rheological and physicochemical properties. The aim is to modify the Bellehumeur model to the case of two different polymers. Thus, it is necessary to investigate the effect of viscosity, surface tension and relaxation of each polymer grain on kinetic model. The use of such approaches allowed us to transpose the Bellehumeur's model to the case of two different grains by including corrector factors. In fact, when the polymers grains merge, an interphase is formed between them. The results indicate that the modified Bellehumeur model proposed presents a good correspondence with the experimental results obtained by microscopy.

Finally, to support and deepen this study, we carried out simulation of this phenomenon using in one hand Fluent software and in the other hand a meshless methods for numerical simulation in mechanics which is called SPH (Smoothed Particle Hydrodynamics) [4]. 


\section{References}

[1] C. Huang and L. Zhang, "Miscibility of poly(vinylidene fluoride) and atactic poly(methyl methacrylate)," J. Appl. Polym. Sci., vol. 92, no. 1, pp. 1-5, 2004.

[2] C. T. Bellehumeur, "Polymer sintering and its role in rotational molding," 1997.

[3] A. Hamidi et al., "Modelling of sintering during rotational moulding of the thermoplastic polymers," Int. J. Mater. Form., vol. 9, no. 4, pp. 519-530, 2016.

[4] M. Kelager, "Lagrangian fluid dynamics using smoothed particle hydrodynamics," Univ. Cph. Dep. Comput. Sci., 2006. 